\title{
Detecção de resíduos de antibióticos em amostras de leite pasteurizado do Estado do Paraná, Brasil
}

\section{Detection of antibiotic residues in pasteurized milk samples from Paraná State, Brazil}

\author{
Thállitha Samih Wischral Jayme Vieira ${ }^{1 *}$; Milene Rochedo Ribeiro²; \\ Maurício Pinto Nunes ${ }^{3}$; Miguel Machinski Júnior ${ }^{4}$; Daisy Pontes Netto ${ }^{5}$
}

\section{Resumo}

O leite é um alimento essencial na dieta humana e por este motivo deve apresentar condições sanitárias adequadas e ausência de contaminantes químicos e baixa contaminação microbiana. Os resíduos de antibióticos são considerados como os principais contaminantes químicos do leite e representam risco potencial à saúde do consumidor. Assim, objetivou-se detectar os resíduos de antibióticos em 79 amostras de leite pasteurizado do tipo $\mathrm{B}$ de diferentes fabricantes adquiridos em estabelecimentos comerciais do Estado do Paraná, Brasil. A detecção de residuos de estreptomicina, cloranfenicol, $\beta$-lactâmicos, tetraciclina e gentamicina foi realizada utilizando kits comerciais de ensaio imunoenzimático. Foram detectados resíduos de antibióticos em 15/79 (19\%), das quais 6/15 (40\%) estavam contaminadas por cloranfenicol, $3 / 15(20 \%)$ por tetraciclinas, $1 / 15(6,7 \%)$ por gentamicina, $3 / 15(20 \%)$ por estreptomicina e $2 / 15(13.3 \%)$ por $\beta$-lactâmicos e três amostras estavam contaminadas por dois tipos de resíduo simultaneamente. A legislação brasileira regulamenta que os resíduos de antibióticos e outros agentes inibidores de crescimento microbiano devem estar ausentes. Assim, estudos devem ser realizados para a quantificação desses resíduos visando o monitoramento do risco de exposição aos consumidores.

Palavras-chave: Leite, resíduos de antibióticos, ensaio imunoenzimático

\begin{abstract}
Milk is an essential food on human's diet and for this reason must provide adequate sanitary conditions and lack of chemical and low level of microbial contamination. Antibiotics residues are considered as the main chemical contaminant of milk and represent potential risk to the consumer health. Thus, the aim was to detect antibiotics residues in 79 samples of type B pasteurized milk from different manufactures acquired in commercial establishments from Paraná State, Brazil. The detection of streptomycin, chloramphenicol, $\beta$-lactamic, tetracycline and gentamicin residues was performed using commercial immunoenzymatic kits. Antibiotic residues were detected in 15/79 (19\%), which 6/15 (40\%) were contaminated by chloramphenicol, $3 / 15(20 \%)$ by tetracycline, $1 / 15(6.7 \%)$ by gentamicin, $3 / 15(20 \%)$ by streptomycin, and $2 / 15(13.3 \%)$ by $\beta$-lactams and three samples were contaminated by two types of residues simultaneously. Brazilian legislation regulates that residues of antibiotics and other inhibitors of microbial growth should be absent. Thus, further studies should be conducted for quantification of these residues targeting monitoring the exposure risk for consumers.
\end{abstract}

Key words: Milk, antibiotics residues, immunoenzymatic assay

\footnotetext{
${ }^{1}$ Discente de Mestrado do Programa de Pós-Graduação em Ciência Animal, Universidade Estadual de Londrina, UEL, Londrina, PR. E-mail: vieiratswj@gmail.com

${ }^{2}$ Médica Veterinária Residente, UEL, Londrina, PR. E-mail: mi.rochedo@gmail.com

${ }^{3}$ Médico Veterinário da Vigilância Sanitária, Londrina, PR. E-mail: mauricionunes@sesa.pr.gov.br

${ }^{4}$ Prof. Dr. do Dept ${ }^{\circ}$ de Ciências Básicas da Saúde, Universidade Estadual de Maringá, UEM, Maringá, PR. E-mail: mmjunior@, uem.br

${ }^{5} \operatorname{Prof}^{\mathrm{a}} \mathrm{Dr}^{\mathrm{a}}$ do Dept ${ }^{\mathrm{o}}$ de Medicina Veterinária Preventiva, UEL, Londrina, PR. E-mail: rnetto@uel.br

${ }^{*}$ Autor para correspondência
} 
O leite é considerado um alimento de alto valor nutricional por ser fonte de carboidratos, vitaminas, sais mineiras e proteínas, essenciais na dieta humana. Embora o consumo nacional seja considerado baixo, aproximadamente 120 litros por habitante/ano (ZOCCAL, 2009), o Brasil ocupa o sexto lugar no ranking de produção mundial de leite e apresenta uma taxa de crescimento de $4 \%$ ao ano, sendo o Paraná o terceiro estado responsável pela produção anual (EMBRAPA, 2008). Considerando a importância na dieta, o leite deve apresentar condições sanitárias adequadas e ausência de contaminação ou substâncias impróprias (MENDES et al., 2008).

A contaminação do leite por agentes químicos tem ocorrência mundial, sendo os resíduos de antimicrobianos encontrados constantemente (NERO et al., 2007). A presença desses resíduos no leite é consequência da utilização indiscriminada de medicamentos na prática veterinária, não cumprimento do período de carência dessas substâncias (PONTES NETTO et al., 2005), higienização inadequada de equipamentos e utensílios da indústria ou adição fraudulenta para minimizar a deficiência da qualidade higiênica do leite (BORGES et al., 2000).

O leite com a presença de resíduos de substâncias químicas é considerado adulterado e impróprio para o consumo, pois representa um risco à saúde pública (MENDES et al., 2008). Estes riscos são manifestados por reações de hipersensibilidade, frequentemente associadas as penicilinas ( $\beta$-lactâmicos) e as estreptomicinas; indução de resistência bacteriana, associada as tetraciclinas; lesões óticas, hepáticas e renais associadas a gentamicina, além de genotoxicidade e anemia aplásica associadas ao cloranfenicol (LOZANO; ARIAS, 2008). A maioria da população humana é frequentemente exposta a baixas doses destes contaminantes, o que resulta em efeitos a longo prazo (BIACCHI; JORGE; UENO, 2004).

Com o objetivo de avaliar e prevenir estes riscos, o Ministério da Saúde implantou no Brasil o Programa de Análise de Resíduos de Medicamentos Veterinários em Alimentos (PAMvet), o qual elegeu o leite como primeiro alimento a ser analisado (ANVISA, 2005). Para as análises e monitoramento de resíduos de antimicrobianos são utilizados métodos de triagem como o de inibição microbiana e testes imunológicos (OLIVEIRA; BANDO; MACHINSKI JUNIOR, 2007). O ensaio imunoenzimático (ELISA) é um método amplamente utilizado em razão da sua sensibilidade, especificidade, praticidade e rapidez de execução (MORAIS et al., 2010), permitindo que várias amostras sejam analisadas em um período curto de tempo. Entretanto, as amostras positivas devem ser submetidas a testes confirmatórios utilizando técnicas analíticas de maior sensibilidade e especificidade (OLIVEIRA; BANDO; MACHINSKI JUNIOR, 2007).

Considerando a grande importância em saúde pública e a eficiência dos testes de monitoramento, esse trabalho teve como objetivo detectar resíduos de antimicrobianos (estreptomicina, cloranfenicol, $\beta$-lactâmicos, tetraciclina e gentamicina) em leite comercializado no Estado do Paraná, utilizando kits de ELISA.

Foram coletadas aleatoriamente, 79 amostras de leite pasteurizado tipo B, de diferentes marcas, provenientes de estabelecimentos comerciais do Estado do Paraná. As coletas foram realizadas durante o período de março a outubro de 2008, pelas Regionais da Secretaria de Saúde do Estado do Paraná - SESA/PR, como parte do PAMvet-PR.

As amostras foram mantidas sob refrigeração até o recebimento no Laboratório de Toxicologia Veterinária do Departamento de Medicina Veterinária Preventiva da Universidade Estadual de Londrina (UEL). Após homogeneização da amostra, separouse uma alíquota de $350 \mathrm{~mL}$ de cada embalagem que foram distribuídas em frascos plásticos de $80 \mathrm{~mL}$, devidamente identificados e armazenados a $-20^{\circ} \mathrm{C}$ até o processamento. 
A detecção de estreptomicina e cloranfenicol foi realizada utilizando kits comerciais de ELISA (RIDASCREEN ${ }^{\circledR} \quad$ Chloramphenicol, RIDASCREEN $^{\circledR}$ Streptomycin, R-Biopharm AG, Darmstadt, Germany) de acordo com as instruções do fabricante. Para a leitura das placas foi utilizado espectrofotômetro de leitura automática $\left(\right.$ Emax $^{\circledR}$, Molecular Devices Corporation, Califórnia, EUA) e o programa RIDA ${ }^{\circledR}$ SOFT Win (R-Biopharm AG, Darmstadt, Germany) para os cálculos das curvas de calibração e concentração das amostras. O limite de detecção e quantificação dos testes é de 25 ppt para cloranfenicol e $10 \mathrm{ppb}$ para estreptomicina. Foram consideradas positivas as amostras com resultados superiores ao limite de quantificação do método. A detecção de $\beta$-lactâmicos, tetraciclina e gentamicina foi realizada utilizando kits comerciais $\left(\beta\right.$ L SNAP ${ }^{\circledR}$ Test, Tetracycline SNAP $^{\circledR}$ Test, Cite Probe Gentamicin SNAP ${ }^{\circledR}$ Test, Idexx Laboratories, Maine, EUA) de acordo com as instruções do fabricante.

Resíduos de antimicrobianos foram detectados em 15/79 (19\%) amostras analisadas. Do total de amostras positivas, 6/15 (40\%) estavam contaminadas por cloranfenicol, 3/15 (20\%) por tetraciclinas, $1 / 15(6,7 \%)$ por gentamicina, $3 / 15$ (20\%) por estreptomicina e $2 / 15$ (13.3\%) por $\beta$-lactâmicos. Destas, três amostras estavam contaminadas por mais de um tipo de antimicrobiano.

Os resultados observados diferem dos encontrados por Folly e Machado (2001) que obtiveram 3,33\% das amostras positivas para $\beta$-lactâmicos e tetraciclinas em amostras de leite tipo C e Integral Fazenda do comércio da Região Norte do Estado do Rio de Janeiro. Com relação aos resíduos de cloranfenicol, o resultado obtido foi superior ao de Oliveira, Bando e Machinski Junior (2007) que detectou $2,6 \%$ de positividade em amostras de leite pasteurizado no estado do Paraná. Embora o uso de cloranfenicol seja proíbido em animais de produção pela legislação brasileira (BRASIL, 1999), os resultados apresentados evidenciam que este composto ainda está sendo utilizado.
Nos anos de 2006 e 2007, 615 amostras de leite de diferentes estados foram coletadas e analisadas pelo Pamvet, utilizando a mesma metodologia do presente estudo. Verificou-se que $1 \%$ das amostras foram positivas para $\beta$-lactâmicos, 4,9\% para tetraciclinas, 3,6\% para estreptomicina e 10,3\% para cloranfenicol. Do total de amostras coletadas no Estado do Paraná, 1,7\% foram positivas para $\beta$-lactâmicos, $10,5 \%$ para tetraciclinas, $1,7 \%$ para cloranfenicol e 3,5\% para estreptomicina (ANVISA, 2009). Comparando com os dados encontrados no presente estudo, verificou-se um aumento da contaminação por resíduos de antibióticos no leite comercializado no Paraná entre os anos de 2006 e 2008. Assim, é possível supor que os antibióticos estão sendo cada vez mais utilizados ou o período de carência estabelecido para os medicamentos não está sendo cumprido.

Desta forma, pessoas que tenham o hábito de consumir leite estão ingerindo constantemente resíduos de antibióticos o que pode ocasionar reações alérgicas, resistência bacteriana e, em casos extremos, levar a óbito. Além disso, pode ocorrer a ingestão de mais de um resíduo de antibiótico, como foi constatado em três amostras de leite, o que aumentaria o risco a saúde do consumidor. A presença destes resíduos assume maior importância quando o leite é considerado como matéria-prima, visto que o processo de pasteurização não degrada os resíduos, permanecendo nos seus derivados.

Outros estudos conduzidos com diferentes métodos de detecção também tem demonstrado a ocorrência de resíduos de medicamentos em amostras de leite provenientes de diversas regiões do Brasil. Utilizando um protocolo de inibição microbiana foi detectada a presença de resíduos de antimicrobianos em 9,95\% das amostras de leite pasteurizado integral e padronizado, no estado de Goiás (BORGES et al., 2000), já no estado de São Paulo, em uma cooperativa na região do Vale do Paraíba, 100\% das amostras de leite pasteurizado tipo B e $80 \%$ do tipo C estavam contaminadas por resíduos de antibióticos (BIACCHI; JORGE; 
UENO, 2004). Em outro estudo, 11,4\% das amostras de leite cru de propriedades leiteiras de diferentes regiões brasileiras apresentavam resíduos de antibióticos, sendo o estado do Paraná responsável pelo maior número de resultados positivos (NERO et al., 2007). A presença dos resíduos no leite tem sido atribuída ao uso inadequado de antibióticos e/ ou descumprimento do tempo de carência indicado após a última aplicação do medicamento no animal, antes de realizar a ordenha e destinar o leite ao consumo humano (BORGES et al., 2000).

Embora vários estudos sejam realizados com o intuito de detectar rapidamente a presença de antimicrobianos no leite, estes são isolados e eventuais, o que impede o reconhecimento confiável da situação do país. Sendo assim, em 2002, a Anvisa iniciou o Pamvet que tem como objetivo estabelecer um delineamento e controle sobre estes resíduos no Brasil (ANVISA, 2005). Entretanto, o sucesso dos programas governamentais depende de mudanças de atitude e de manejo dos produtores (MENDES et al., 2008). A legislação brasileira não permite a presença de resíduos de antibióticos e outros agentes inibidores de crescimento microbiano (BRASIL, 2002). Assim, é necessário maior atenção por parte dos serviços oficiais de inspeção no controle sanitário desde a ordenha até a comercialização do leite.

O leite comercializado no Estado do Paraná apresentou contaminação por resíduos de antimicrobianos em 15,2\% das amostras analisadas. Embora tenha sido usado método qualitativo, o leite analisado constitui um risco para a saúde do consumidor, visto que esses resíduos permanecerão nesta matriz alimentar e em seus derivados. A quantificação desses resíduos se torna importante para o monitoramento do nível de contaminação na alimentação, definindo, assim, o risco de exposição aos consumidores.

\section{Agradecimentos}

Aos técnicos das Vigilâncias Sanitárias das Regionais de Saúde da SESA/PR e das Secretarias Municipais de Saúde: Eliana da Silva Scucato, Ivana Lúcia Belmonte, Ailton Benini, Luciana Maria Borba, Angelo Garbossa Neto, Mariela M. M. Goularte, Ana Maria Itinose, Roselane Langer, Márcia Oliveira Lopes, José Schiarolli, Cláudio Sobesak, Dirceu Vedovello Filho e a técnica de laboratório Aparecida Maria de Oliveira pelo auxílio na prestado para a realização do trabalho.

\section{Referências}

AGÊNCIA NACIONAL DE VIGILÂNCIA SANITÁRIA - ANVISA. Brasília: ANVISA, 2005. Disponível em: <http://www.anvisa.gov.br/alimentos/ pamvet/relatorio_02_03.pdf $>$. Acesso em: 04 ago. 2010.

Brasília: ANVISA, 2009. Disponível em: http://websphere.anvisa.gov.br/wps/wcm/connect/ ba64428041 ece36fb8d5fd255d42da10/PAMVET. pdf?MOD=AJPERES $>$. Acesso em: 06 ago. 2010.

BIACCHI, N. C.; JORGE, A. O. C.; UENO, M. Detecção de resíduos antibióticos em leite bovino na região do Vale do Paraíba, São Paulo. Revista Biociências, Taubaté, v. 10, n. 1-2, p. 47-49, 2004.

BORGES, G. T.; SANTANA, A. P.; MESQUITA, A. J.; MESQUITA, S. Q. P.; SILVA, L. A. F.; NUNES, V. Q. Ocorrênciade resíduos de antibióticos em leite pasteurizado integral e padronizado produzido e comercializado no estado de goiás. Ciência Animal Brasileira, Goiás, v. 1, n. 1, p. 59-63, 2000.

BRASIL. Ministério da Agricultura Pecuária e Abastecimento. Instrução Normativa $\mathrm{n}^{\circ} 42$, de 20 de Dezembro de 1999. Disponível em: <http://extranet. agricultura.gov.br/sislegis-consulta/consultar Legislacao. do?operacao=visualizar\&id $=16717>$. Acesso em: 04 ago. 2010.

Instrução Normativa $\mathrm{N}^{\circ} 51$ De 18 de Setembro de 2002. Disponível em: <http://extranet.agricultura. gov.br/sislegis-consulta/consultarLegislacao.do?operaca $\mathrm{o}=$ visualizar\&id=8932> . Acesso em: 04 ago. 2010.

EMPRESA BRASILEIRA DE PESQUISA AGROPECUÁRIA - EMBRAPA. Brasília: EMBRAPA, 2008. Disponível em: <http://www.cnpgl.embrapa.br/ nova/informacoes/estatisticas/consumo/consumo.php>. Acesso em: 23 ago. 2010. 
FOLLY, M. M.; MACHADO, S. C. A. Determinação de resíduos de antibióticos, utilizando-se métodos de inibição microbiana, enzimático e imunoensaios no leite pasteurizado comercializado na região norte do estado do rio de janeiro, Brasil. Ciência Rural, Santa Maria, v. 31, n. 1, p. 95-98, 2001.

LOZANO, M. C.; ARIAS, D. C. Residuos de fármacos en alimentos de origen animal: panorama actual en Colombia. Revista Colombiana de Ciencias Pecuarias, Colombia, v. 21, n. 1, p. 121-135, 2008.

MENDES, C. G.; SAKAMOTO, S. M.; SILVA, J. B. A.; LEITE, A. Í. Pesquisa de resíduos de beta-lactâmicos comercializado clandestinamente no município de Mossoró, RN, utilizando o delvotest sp. Arquivos do Instituto Biológico, São Paulo, v. 75, n. 1, p. 95-98, 2008.

MORAIS, C. M. Q. J.; DURÃES, T. S.; NÓBREGA, A. W.; JACOB, S. C. Presença de resíduos de antibióticos em leite bovino pasteurizado. Ciência e Tecnologia de Alimentos, Campinas, v. 30, n. 1, p. 33-35, 2010.

NERO, L. A.; MATTOS, M. R.; BELOTI, V.; BARROS, M. A. F. ; FRANCO, B. D. G. M. Resíduos de antibióticos em leite cru de quatro regiões leiteiras no Brasil. Ciência e Tecnologia de Alimentos, Campinas, v. 27, n. 2, p. 391393, 2007.

OLIVEIRA, C. R.; BANDO, E.; MACHINSKI JUNIOR, M. Ocorrência de cloranfenicol em leite pasteurizado comercializado no Estado do Paraná, Brasil. Acta Scientiarum. Health Science, Maringá, v. 29, n. 1, p. 5962, 2007.

PONTES NETTO, D.; LOPES, M. O.; OLIVEIRA, M. C. S.; NUNES, M. P.; MACHINSKI JUNIOR, M.; BOSQUIROLI, S. L.; BENATTO, A.; BENINI, BOMBARDELLI, A. L. C.; VEDOVELLO FILHO, D.; MACHADO, E.; BELMONTE, I. L.; ALBERTON, M.; PEDROSO, P. P.; SCUCATO, E. S. Levantamento dos principais fármacos utilizados no rebanho leiteiro do Estado do Paraná. Acta Scientiarum. Animal Sciences, Maringá, v. 27, n. 1, p. 145-151, 2005.

ZOCCAL, R. O leite que o Brasil precisa. Brasília: EMBRAPA, 2009. Disponível em: <http://www. embrapa.br/imprensa/artigos/2009/o-leite-de-que-obrasil-precisa/>. Acesso em: 23 ago. 2010. 
